\title{
Desenvolvimento radicular e aéreo, nutrição e eficiência de absorção de macronutrientes e zinco por cultivares de arroz de terras altas afetadas pela adubação fosfatada
}

\author{
Root and shoot development, nutrition and uptake efficiency of \\ macronutrients and zinc by upland rice cultivars as affected by \\ phosphorus fertilization
}

\author{
Carlos Alexandre Costa Crusciol ${ }^{1 *}$; Adriano Stephan Nascente ${ }^{2 *}$; \\ Munir Mauad ${ }^{3}$; Ana Claudia de Lima Silva ${ }^{4}$
}

\begin{abstract}
Resumo
No Brasil, a disponibilidade de fósforo é um dos fatores que mais limita a produtividade do arroz de terras altas no sistema de sequeiro. Assim, o conhecimento do desenvolvimento das cultivares melhoradas à níveis de fósforo no solo é de grande importância no manejo dos sistemas de produção, tornando-os mais sustentáveis. O objetivo deste trabalho foi avaliar a influência das doses de fósforo aplicados no solo sobre o comprimento radicular, de massa seca da raiz e da parte aérea, os teores e acúmulo de macronutrientes e zinco na parte aérea e no sistema radicular, bem como a eficiência de absorção dos nutrientes por metro de raiz em cultivares de arroz de terras altas dos grupos intermediário e moderno. $\mathrm{O}$ experimento foi conduzido em casa de vegetação no delineamento experimental inteiramente casualizado em esquema fatorial $4 \times 4$, com quatro repetições. Os tratamentos foram constituídos de quatro doses de fósforo $\left(0,50,100\right.$ e $200 \mathrm{mg} \mathrm{dm}^{-3} \mathrm{de}$ P) e quatro cultivares de arroz (Maravilha - grupo moderno, IAC-201, IAC-202 e Carajás - grupo intermediário). Houve aumento da disponibilidade de fósforo no solo com o aumento das doses aplicadas. Sob baixa disponibilidade de fósforo as cultivares do grupo intermediário tiveram maior desenvolvimento do sistema radicular e da parte aérea em relação a cultivar do grupo moderno. O aumento da dose de fósforo incrementou os teores de nutrientes no sistema radicular e na parte aérea das cultivares de arroz. A adubação crescente de fósforo favoreceu o aumento da absorção dos nutrientes por metro de raiz; e apesar de ter sido constatado maior crescimento radicular devido a maior disponibilidade de fósforo, sob baixa disponibilidade desse nutriente, o crescimento radicular foi maior em detrimento do crescimento da parte aérea.
\end{abstract}

Palavras-chave: Oryza sativa L., nutrientes, sistema radicular, cultivo em vaso

\begin{abstract}
In Brazil, phosphorus availability is one factor that that more limit yield of upland rice under rainfed system. Then, better understanding of cultivars development at phosphorus soil fertilization is very important in the production systems making this more sustainable. The objective was to evaluate
\end{abstract}

\footnotetext{
${ }^{1}$ Eng $^{\mathrm{o}}$ Agr $^{\mathrm{o}}$, Prof. Titular do Dept ${ }^{\mathrm{o}}$ de Produção Vegetal, DPV, Faculdade de Ciências Agronômicas, FCA, Universidade Estadual Paulista, UNESP. C P 237, CEP 18603-970. Botucatu, SP. Bolsista CNPp. E-mail: crusciol@fca.unesp.br

${ }^{2}$ Eng $^{\mathrm{o}} \mathrm{Agr}^{\mathrm{o}}$, Pesquisador Embrapa Arroz e Feijão, Santo Antônio de Goiás, GO. E-mail: adriano@cnpaf.embrapa.br

${ }^{3}$ Eng $^{\text {o }}$ Agr $^{\mathrm{O}}$, Prof. da Faculdade de Ciências Agrárias, Universidade Federal da Grande Dourados, UFGD, Dourados, MS. E-mail: munirmauad@ufgd.edu.br

${ }^{4}$ Eng $^{\mathrm{a}} \mathrm{Agr}^{\mathrm{a}}$, Discente de Mestrado em Agronomia, Área de concentração Agricultura do Dept ${ }^{\circ}$ de Produção Vegetal, DPV, UNESP, Botucatu, SP. E-mail: analima.agro@gmail.com

* Autor para correspondência
} 
the influence of phosphorus doses applied to the soil over the root length, root and shoot dry matter, concentration and content of macronutrient and zinc in shoot and root as well as the efficiency of nutrient uptake per meter root of upland cultivars of intermediate and modern groups. The experiment was carried out in greenhouse conditions in a completely randomized design in factorial scheme $4 \times 4$. Treatments were four levels of $P$ fertilization applied at the soil $\left(0,50,100\right.$ and $\left.200 \mathrm{mg} \mathrm{dm}^{-3} \mathrm{of} \mathrm{P}\right)$ and four upland rice cultivars (Maravilha - modern group, IAC-201, IAC-202 and Carajás - intermediate group). There is increase in phosphorus availability in the soil with increasing levels of $\mathrm{P}$ fertilization. Under low phosphorus availability, cultivars of the intermediate group have better shoots and root system development in relation to the modern cultivar group. Level of phosphorus affected nutrients contents in shoots and root system of upland rice cultivars. The increasing phosphorus fertilization increased uptake of nutrients per meter of root; and although under higher phosphorus availability there was a greater root growth, in low phosphorus availability root growth was greater at the expense of shoot growth.

Key words: Oryza sativa L., nutrients, root, plant growing in pots

\section{Introdução}

Apesar do arroz de terras altas ser cultivado quase exclusivamente no Brasil (SANTOS; STONE; VIEIRA, 2006), sua importância vem aumentando, uma vez que com a redução da água disponível para a produção irrigada do arroz na Ásia, devido ao aumento da demanda pelas indústrias e população, é necessário o desenvolvimento de alternativas visando a produção com maior economia desse recurso natural (FENG et al., 2007; QU et al., 2008).

A maioria dos solos onde se cultiva o arroz de terras altas tem baixa capacidade de retenção de água, baixo teor de fósforo e alto teor de alumínio, sendo os três fatores que mais limitam a produção no cerrado (GUIMARÃES; STONES; NEVES, 2007; FAGERIA, 2009). Adicionalmente, com a modernização e racionalização da agricultura brasileira, a utilização de uma adubação adequada torna-se fator de destaque (NASCENTE et al., 2011a), uma vez que, o fornecimento adequado e equilibrado de nutrientes, pelo uso de fertilizantes, favorece o bom desenvolvimento das culturas (FAGERIA; BALIGAR; LI, 2008; FAGERIA; MOREIRA; COELHO, 2011a; NASCENTE et al., 2011b).

Além disso, cultivares com maior crescimento radicular e maiores capacidades de aquisição de água e nutrientes são de fundamental importância para a produção vegetal, principalmente em regiões sujeitas à veranicos e com solos com baixa capacidade de retenção de água (OLIVEIRA JUNIOR; PROCHNOW; KLEPKER, 2011). Com isso, há exploração de maior volume de solo, que é importante mecanismo adaptativo da planta para garantir a absorção de P (HORST et al., 2001; GUIMARÃES; STONES; NEVES, 2007; FAGERIA; BALIGAR, 2008; ROTILI et al., 2010). Aumentando o conhecimento sobre a dinâmica do desenvolvimento das raízes do arroz poderia aumentar a eficiente de uso dos nutrientes aplicados, tornando os sistemas de produção mais sustentáveis, pois refletiria diretamente em adubações mais racionais de acordo com a exigência das cultivares (FAGERIA; MOREIRA, 2011).

Segundo Fageria e Stone (2006) e Fageria e Moreira (2011) o padrão de enraizamento está sob controle genético, porém o crescimento das raízes pode ser modificado por características químicas e físicas do solo. Estudos de adubação fosfatada têm demonstrado aumento da massa seca de raiz com incremento na absorção de nutrientes nas culturas do milho, soja, algodão (FAGERIA; STONE, 2006; FAGERIA; MOREIRA, 2011). Na cultura do arroz de terras altas, os resultados obtidos não foram diferentes, havendo, com o aumento da disponibilidade de fósforo, mediante adubação fosfatada, incremento na produção de massa seca da parte aérea e de raiz (ZOBEL, 2003; FAGERIA, 2007; FAGERIA; BALIGAR, 2008; FAGERIA; MOREIRA; COELHO, 2011a; FAGERIA; 
MOREIRA, 2011) e nos teores de N, P, K, Ca e Mg na parte aérea (FAGERIA; BALIGAR; JONES, 2011b).

Adicionalmente, diversos autores comprovaram a existência de algumas diferenças entre cultivares em relação à capacidade de absorção e utilização de nutrientes (SANT'ANA et al., 2003; GUIMARÃES; STONES; NEVES, 2007; ROTILI et al., 2010; FAGERIA; MOREIRA, 2011). Neste sentido, são necessários estudos para avaliar o comportamento do sistema radicular e parte aérea de cultivares de arroz em relação a adição de fósforo ao solo.

De maneira geral, os cultivares do tipo tradicional são caracterizados por terem porte alto, com folhas longas e decumbentes, baixa capacidade de perfilhamento, boa resistência a doenças de importância secundária, maior estabilidade produtiva em relação aos do tipo moderno em condições adversas, acamamento em solos férteis ou quando adubados com doses elevadas de nitrogênio, bem como quando recebem maior aporte tecnológico no sistema de produção, e possuem grãos longos e vítreos. Os do tipo moderno caracterizam-se por plantas de porte baixo, folhas curtas e eretas, colmos fortes, elevado perfilhamento, respondem em produtividade de grãos a altos níveis tecnológicos, como adubação, sem acamar, e grãos geralmente longos e finos. Por fim, os do tipo intermediário são cultivares resultantes do cruzamento de materiais do tipo tradicional com os do tipo moderno, objetivando a redução do porte da planta e a melhoria da qualidade do grão, exigindo, teoricamente nível tecnológico entre ambos os grupos precursores (SANTOS; STONE; VIEIRA, 2006).

Diante do exposto, materiais intermediários e modernos podem ter diferenças quanto à absorção e acúmulo de nutrientes, podendo ter comportamento distintos com a aplicação de fósforo. O objetivo foi avaliar a influência do aumento de doses de fósforo aplicadas no solo sobre o comprimento de raiz, massa seca de raiz e parte aérea, teores e acúmulos de macronutrientes e zinco na parte aérea e no sistema radicular, bem como a eficiência de absorção dos nutrientes por metro de raiz em cultivares de arroz de terras altas dos grupos intermediário e moderno.

\section{Material e Métodos}

O experimento foi conduzido em casa de vegetação do Departamento de Produção Vegetal Agricultura, da Faculdade de Ciências Agronômicas - FCA, da Unesp, em Botucatu-SP, onde utilizouse solo oriundo da camada arável $(0$ a $20 \mathrm{~cm})$ de um Latossolo Vermelho Distroférrico (EMBRAPA, 2006) de textura média, com as seguintes características: $\mathrm{pH}\left(\mathrm{CaCl}_{2}\right)=4,1$; $\mathrm{M} . \mathrm{O}=18,0 \mathrm{~g} \mathrm{~kg}^{-1}$; $\mathrm{S}_{-} \mathrm{SO}_{4}{ }^{2-}=7 \mathrm{mg} \mathrm{dm}{ }^{-3} ;$ P-resina $=1 \mathrm{mg} \mathrm{dm}^{-3} ; \mathrm{K}^{+}=0,1$ $\mathrm{mmol}_{\mathrm{c}} \mathrm{dm}^{-3} ; \mathrm{Ca}^{++}=4 \mathrm{mmol}_{\mathrm{c}} \mathrm{dm}^{-3} ; \mathrm{Mg}^{++}=1 \mathrm{mmol}_{\mathrm{c}}$ $\mathrm{dm}^{-3} ; \mathrm{H}+\mathrm{Al}=75 \mathrm{mmol}_{\mathrm{c}} \mathrm{dm}^{-3} ; \mathrm{CTC}=58 \mathrm{mmol}_{\mathrm{c}} \mathrm{dm}^{-3}$ e $\mathrm{V}=6,4 \%$.

O delineamento experimental foi inteiramente casualizado em esquema fatorial 4 x 4, com quatro repetições. Assim, os tratamentos foram constituídos de quatro doses de fósforo $(0,50,100$ e $200 \mathrm{mg}$ de $\mathrm{P} \mathrm{dm}{ }^{-3}$ ) e quatro cultivares de arroz (Maravilha - grupo moderno, IAC-201, IAC-202 e Carajás - grupo intermediário). As doses foram definidas segundo recomendações de Malavolta (2006), visando a não ocorrência de deficiência $\left(100 \mathrm{mg} \mathrm{dm}^{-3}\right)$ e haver um excesso $\left(200 \mathrm{mg} \mathrm{dm}^{-3}\right)$. Cada unidade experimental constitui-se de um vaso plástico de $10 \mathrm{~L}$, contendo $8 \mathrm{~kg}$ de solo.

Trinta dias antes da aplicação do fósforo aplicouse calcário dolomítico (PRNT = 93\%) para elevar a saturação por bases a $70 \%$, segundo recomendação de Malavolta (2006). Após o período de incubação e cinco dias antes da semeadura, cada vaso recebeu $100 \mathrm{mg} \mathrm{dm}^{-3}$ de $\mathrm{N}\left(50 \mathrm{mg} \mathrm{dm}^{-3}\right.$ na semeadura e $50 \mathrm{mg} \mathrm{dm}^{-3}$ em cobertura no início do estádio de perfilhamento), $150 \mathrm{mg} \mathrm{dm}^{-3}$ de $\mathrm{K}$, utilizando-se uréia $(42 \%$ de $\mathrm{N})$ e cloreto de potássio $\left(60 \%\right.$ de $\left.\mathrm{K}_{2} \mathrm{O}\right)$ como fonte de $\mathrm{N}$ e $\mathrm{K}$, respectivamente, juntamente com a aplicação dos tratamentos com $\mathrm{P}$, na forma de 
superfosfato simples $\left(22 \%\right.$ de $\left.\mathrm{P}_{2} \mathrm{O}_{5}\right)$. Os fertilizantes foram aplicados e misturados na terra de cada vaso por meio de uma betoneira.

As cultivares utilizadas possuem as seguintes características: Maravilha: pertence ao grupo moderno com plantas de porte baixo, folhas curtas, eretas, colmos fortes, alto perfilhamento e respondem, sem acamar, à melhoria da fertilidade do solo e a adubação nitrogenada, IAC 201, IAC 202 e Carajás são pertencentes ao grupo intermediário e resultantes do cruzamento de plantas do grupo moderno com plantas do grupo tradicional, esse último caracterizado por plantas de porte alto, folhas longas e decumbentes, baixa capacidade de perfilhamento, acamamento em solos férteis ou quando adubados com elevadas doses de nitrogênio. As cultivares Maravilha e a IAC-202 possuem ciclo médio e grãos tipo longo e fino com florescimento entre 95-100 e 87-92 dias após a emergência, respectivamente. As cultivares IAC 201 e Carajás possuem ciclo precoce, sendo que a primeira possui grão tipo longo fino e a segunda tipo longo, com florescimento entre 78-90 dias após a emergência para ambas (SANTOS; STONE; VIEIRA, 2006).

Foram semeadas cinco sementes por vasos e uma semana após a emergência foi realizado o desbaste, deixando-se duas plantas por vasos. Aos 79 dias após a emergência, quando as plantas se encontravam no estádio de diferenciação floral (ponto de algodão visível), foi realizada a colheita das plantas, as quais foram seccionadas no colo separando a parte aérea do sistema radicular.

A parte aérea foi lavada em água corrente e a seguir submetida à secagem, em estufa com circulação forçada de ar, a $65^{\circ} \mathrm{C}$, e pesada para a determinação da massa seca da parte aérea. As raízes foram separadas do solo por lavagem em água corrente sobre peneira com malha de 0,5 $\mathrm{mm}$. Após a lavagem de todo o sistema radicular de cada unidade experimental, foi tomada uma amostra constituída de $30 \%$ do peso fresco, extraída no sentido do comprimento, ou seja, do ponto de surgimento das raízes adventícias, no colo da planta, até a extremidade do sistema radicular. Em seguida, foi avaliado o comprimento radicular por meio da digitalização de imagem, utilizando scanner HP Scanjet 4c/T e o software WinRHIZO Reg. 3.8b (Regent Instruments Inc.), utilizando o metodologia proposta por Tennant (1975), Rosolem, Silva e Esteves (2003) e Silva et al. (2004). Os 70\% restantes do sistema radicular juntamente com os $30 \%$ utilizados na determinação do comprimento foram secos em estufa a $65^{\circ} \mathrm{C}$, onde, posteriormente foi determinada a massa seca radicular (mg planta $\left.{ }^{-1}\right)$.

Assim, pequenas porções da massa seca da raiz e da parte aérea das plantas de arroz foram separadas para a determinação dos teores de N, P, $\mathrm{K}$, Ca, Mg, S e Zn, conforme Malavolta (2006). Por meio dos dados de produção de massa seca e dos teores de nutrientes da parte aérea, determinou-se a quantidade acumulada em mg planta ${ }^{-1}$ para $\mathrm{N}, \mathrm{P}$, $\mathrm{K}, \mathrm{Ca}, \mathrm{Mg}$ e $\mathrm{S}$, e em mg planta ${ }^{-1}$ para o $\mathrm{Zn}$, pela multiplicação dos valores de teores pelos valores de massa seca. De posse desses resultados, realizouse a determinação das quantidades de nutrientes absorvidos por metro de raiz, em $\mathrm{mg} \mathrm{m}^{-1}$, através da razão: quantidade acumulada de nutrientes da parte aérea e comprimento radicular ${ }^{-1}$, seguindo metodologia semelhante a utilizada por Rosolem, Assis e Santiago (1994).

A eficiência de adaptação à disponibilidade de fósforo foi determinada pela relação: massa seca radicular e matéria seca da parte aérea ${ }^{-1}$, enquanto que a eficiência de utilização do fósforo pela relação: massa seca da parte aérea e quantidade acumulada de fósforo na parte aérea ${ }^{-1}$, como utilizado por Sant'ana et al. (2003) e Fageria (2007).

Os dados foram submetidos à analise de variância e o efeito das doses de fósforo foi determinado pela análise de regressão e as médias entre cultivares foram comparadas pelo teste Tukey a $5 \%$. Para comparar os grupos de variedades foi realizada análise de contrastes a 5\% de probabilidade. 


\section{Resultados e Discussão}

Verificou-se um aumento linear e significativo de $\mathrm{P}$ no solo com o aumento da quantidade aplicada (Figura 1), corroborando com as informações obtidas por Fageria, Baligar e Li (2008). Também foi possível observar que as doses aplicadas não corresponderam o teor estimado; provavelmente, devido aos processos de fixação de $\mathrm{P}$ que ocorrem no solo (LEAL; VELLOSO, 1973; OLIVEIRA JUNIOR; PROCHNOW; KLEPKER, 2011).

Figura 1. Teor de fósforo no solo em função da adubação fosfatada (** significativo a 1\% de probabilidade pelo teste F).

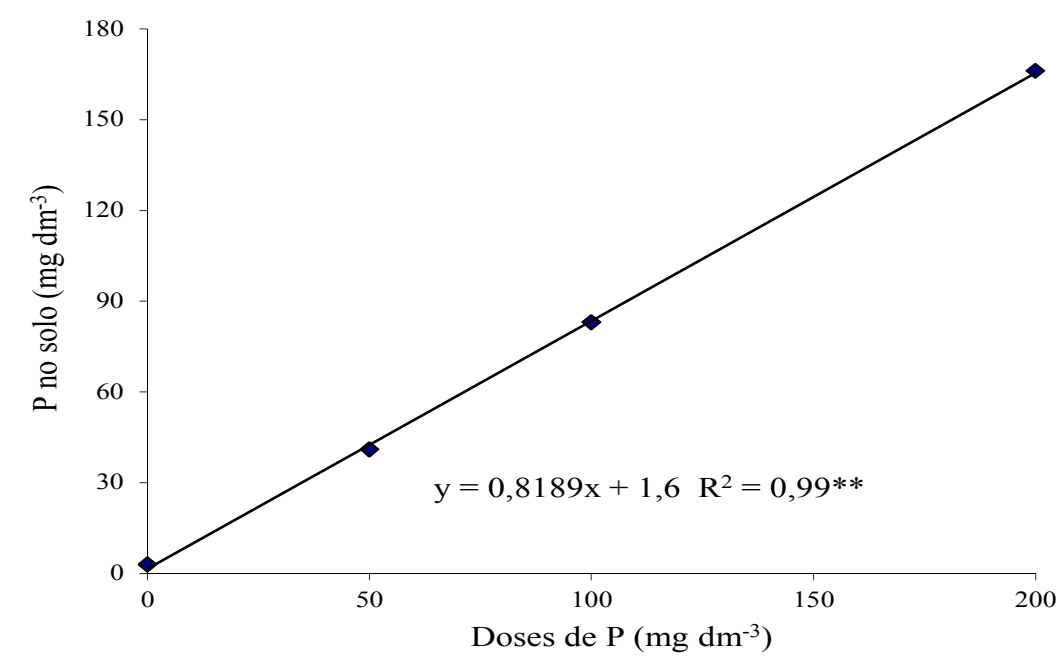

Fonte: Elaboração dos autores.

Observou-se diferenças entre as cultivares em relação aos teores de nutrientes na massa seca da raiz, exceto para os teores de $\mathrm{Mg}$ e $\mathrm{S}$ (Tabela 1). Houve efeito também das doses de fósforo e da interação destes fatores (cultivar x doses de fósforo), exceto para teores de $\mathrm{Ca}$ no sistema radicular das cultivares de arroz (Tabela 1). Com relação aos teores de nutrientes na matéria seca da parte aérea verificou-se também diferenças entre as cultivares quanto ao $\mathrm{N}, \mathrm{K}, \mathrm{Mg}$ e $\mathrm{Zn}$ (Tabela 1). Não houve efeito das doses de fósforo sobre os teores de $\mathrm{Mg}$ e $\mathrm{S}$ e a interação entre os fatores afetou apenas os teores de N, K e Zn.

Em relação às cultivares, verificou-se os menores teores de $\mathrm{N}$ na Maravilha, em ambas as partes, e os maiores de $\mathrm{P}$ e $\mathrm{K}$ no sistema radicular, mas não diferiu quanto ao teor de $\mathrm{P}$ na parte aérea, porém teve os menores teores de K (Tabela 1). Pode-se inferir que as cultivares Carajás, IAC 202 e IAC 201 são mais eficientes no transporte de $\mathrm{P}$ e $\mathrm{K}$ em relação a cultivar Maravilha, neste estádio.

Constatou-se que as cultivares IACs são menos eficientes no transporte de $\mathrm{Ca}$ e mais no de $\mathrm{Mg}$, enquanto, as cultivares Carajás e IAC 202 são mais eficientes no transporte de $\mathrm{Zn}$ em relação as demais (Tabelas 1). Isto possivelmente indica que as características genéticas que controlam a herança da eficiência de absorção e utilização dos nutrientes são independentes entre si, e que ocasionalmente aparecem ao mesmo tempo num mesmo genótipo (SANTOS; STONE; VIEIRA, 2006). 
Tabela 1. Média geral dos teores de nitrogênio, fósforo, potássio, cálcio, magnésio, enxofre e zinco na raiz e na parte aérea de cultivares de arroz e valores de F.

\begin{tabular}{|c|c|c|c|c|c|c|c|}
\hline \multirow[b]{2}{*}{ Cultivares } & \multicolumn{7}{|c|}{ Raiz } \\
\hline & $\mathrm{N}$ & $\mathrm{P}$ & $\mathrm{K}$ & $\mathrm{Ca}$ & $\mathrm{Mg}$ & $\mathrm{S}$ & $\mathrm{Zn}$ \\
\hline & \multicolumn{6}{|c|}{$\mathrm{g} \mathrm{kg}^{-1}$} & $\mathrm{mg} \mathrm{kg}^{-1}$ \\
\hline MARAVILHA & $16,34 \mathrm{~b}$ & $0,67 \mathrm{a}$ & $21,04 \mathrm{a}$ & $13,37 \mathrm{~b}$ & $2,94 \mathrm{a}$ & $3,90 \mathrm{a}$ & $31,94 \mathrm{~b}$ \\
\hline IAC-201 & $17,21 \mathrm{a}$ & $0,61 \mathrm{ab}$ & $18,43 \mathrm{bc}$ & 13,89 a & $3,18 \mathrm{a}$ & $3,78 \mathrm{a}$ & $38,00 \mathrm{a}$ \\
\hline IAC-202 & $17,20 \mathrm{a}$ & $0,44 \mathrm{bc}$ & $17,89 \mathrm{c}$ & $13,69 \mathrm{ab}$ & $3,12 \mathrm{a}$ & $3,95 \mathrm{a}$ & $26,50 \mathrm{c}$ \\
\hline \multirow[t]{2}{*}{ CARAJÁS } & $17,76 \mathrm{a}$ & $0,36 \mathrm{c}$ & $20,21 \mathrm{ab}$ & $13,41 \mathrm{~b}$ & $3,15 \mathrm{a}$ & $4,42 \mathrm{a}$ & $29,88 \mathrm{bc}$ \\
\hline & \multicolumn{7}{|c|}{$\underline{\text { Valor de F }}$} \\
\hline Cultivar (C) & $10,01 * *$ & $8,84 * *$ & $6,35^{* *}$ & $4,31 * *$ & $2,49 \mathrm{~ns}$ & $2,54 \mathrm{~ns}$ & $16,56^{* *}$ \\
\hline Doses de $\mathrm{P}(\mathrm{P})$ & $118,68 * *$ & $97,30 * *$ & $214,55 * *$ & $839,71 * *$ & $167,36^{* *}$ & $28,26^{* *}$ & $442,62 * *$ \\
\hline $\mathrm{CXP}$ & $6,72 * *$ & $7,32 * *$ & $4,51 * *$ & $1,90 \mathrm{~ns}$ & $2,35^{*}$ & $3,92 * *$ & $11,53 * *$ \\
\hline Contraste (M x I) & $10,02 * *$ & $2,52 *$ & $2,74^{*}$ & $2,09 \mathrm{~ns}$ & $1,55 \mathrm{~ns}$ & $1,83 \mathrm{~ns}$ & $2,06 \mathrm{~ns}$ \\
\hline \multirow[t]{2}{*}{ CV (\%) } & 4,32 & 39,21 & 12,11 & 3,51 & 8,82 & 17,23 & 15,04 \\
\hline & \multicolumn{7}{|c|}{ Parte aérea } \\
\hline \multirow[t]{2}{*}{ Cultivares } & $\mathrm{N}$ & $\mathrm{P}$ & $\mathrm{K}$ & $\mathrm{Ca}$ & $\mathrm{Mg}$ & $S$ & $\mathrm{Zn}$ \\
\hline & \multicolumn{6}{|c|}{$\mathrm{g} \mathrm{kg}^{-1}$} & $\mathrm{mg} \mathrm{kg}^{-1}$ \\
\hline MARAVILHA & $28,35 \mathrm{~b}$ & $0,86 \mathrm{a}$ & $23,14 \mathrm{c}$ & $12,94 \mathrm{a}$ & $4,21 \mathrm{~b}$ & $4,16 \mathrm{a}$ & $16,62 \mathrm{~b}$ \\
\hline IAC-201 & 29,67 a & $1,00 \mathrm{a}$ & $25,82 \mathrm{~b}$ & $13,29 \mathrm{a}$ & $4,91 \mathrm{a}$ & $3,44 \mathrm{a}$ & $21,12 \mathrm{a}$ \\
\hline IAC-202 & $30,61 \mathrm{a}$ & $0,87 \mathrm{a}$ & $26,26 \mathrm{~b}$ & $13,88 \mathrm{a}$ & $4,82 \mathrm{a}$ & $3,45 \mathrm{a}$ & $18,88 \mathrm{ab}$ \\
\hline \multirow[t]{2}{*}{ CARAJAS } & 30,06 a & $0,80 \mathrm{a}$ & $28,58 \mathrm{a}$ & $13,53 \mathrm{a}$ & $4,24 \mathrm{~b}$ & $3,60 \mathrm{a}$ & $21,00 \mathrm{a}$ \\
\hline & \multicolumn{7}{|c|}{ Valor de F } \\
\hline Cultivar (C) & $11,09^{* *}$ & $0,68 \mathrm{~ns}$ & $40,54 * *$ & $1,90 \mathrm{~ns}$ & $8,98 * *$ & $1,16 \mathrm{~ns}$ & $11,33^{* *}$ \\
\hline Doses de P (P) & $411,37 * *$ & $34,26^{* *}$ & $234,42 * *$ & $19,48^{* *}$ & $1,39 \mathrm{~ns}$ & $2,37 \mathrm{~ns}$ & $42,52 * *$ \\
\hline $\mathrm{CXP}$ & $4,85^{* *}$ & $1,36 \mathrm{~ns}$ & $5,23 * *$ & $1,92 \mathrm{~ns}$ & $1,70 \mathrm{~ns}$ & $1,02 \mathrm{~ns}$ & $4,90^{* *}$ \\
\hline Contraste $(\mathrm{M} \times \mathrm{I})$ & $13,74 * *$ & $1,54 \mathrm{~ns}$ & $8,55 * *$ & $1,09 \mathrm{~ns}$ & $3,69 *$ & $1,47 \mathrm{~ns}$ & $6,11^{* *}$ \\
\hline CV (\%) & 3,89 & 46,28 & 5,40 & 8,55 & 10,87 & 35,25 & 13,0 \\
\hline
\end{tabular}

Médias seguidas de mesma letra não diferem entre si pelo teste Tukey a 5\%. M e I representam os grupos de cultivares moderno e intermediário, respectivamente. **, * e ns, significativo a $1 \%$ e $5 \%$ e, não significativo, respectivamente.

Fonte: Elaboração dos autores.

Mediante a análise de contraste (Tabela 1) verificou-se que as cultivares do grupo intermediário contém maior teor de $\mathrm{N}$ nas raízes e menores teores de $\mathrm{P}$ e $\mathrm{K}$ que a do grupo moderno. Para os demais nutrientes não houve diferença entre os grupos de cultivares. Na parte aérea os teores de N, K, Mg e Zn foram maiores nas cultivares do grupo intermediário, diferindo da cultivar do grupo moderno.

As produções de massa seca radicular e da parte aérea foram afetadas pelos fatores estudados. Quanto ao desdobramento da interação doses de fósforo dentro de cultivares (Figuras 1 e 2), verificou-se incremento à adubação fosfatada para todas as cultivares.

As cultivares Carajás, IAC 202 e IAC 201 tiveram incremento de forma quadrática para o acúmulo de massa seca de raiz, com as máximas produções nas doses de 124, 155 e $128 \mathrm{mg} \mathrm{dm}^{-3}$ de $\mathrm{P}$, respectivamente (Figura 2). Para a cultivar Maravilha o efeito foi linear, sendo uma cultivar mais responsiva em relação as demais. Segundo Sant'ana et al. (2003), Santos, Stone e Vieira (2006), Rotili et al. (2010) e Fageria, Moreira e Coelho (2011a), cultivares do grupo moderno são mais responsivas a adubação. 
Figura 2. Massa seca raiz (MSPA) e teores de nitrogênio $(\mathrm{N})$, fósforo $(\mathrm{P})$, potássio $(\mathrm{K})$, cálcio $(\mathrm{Ca})$, magnésio $(\mathrm{Mg})$, enxofre(S) e zinco $(\mathrm{Zn})$ na raiz, no estádio de diferenciação floral de cultivares de arroz em função de doses de fósforo.
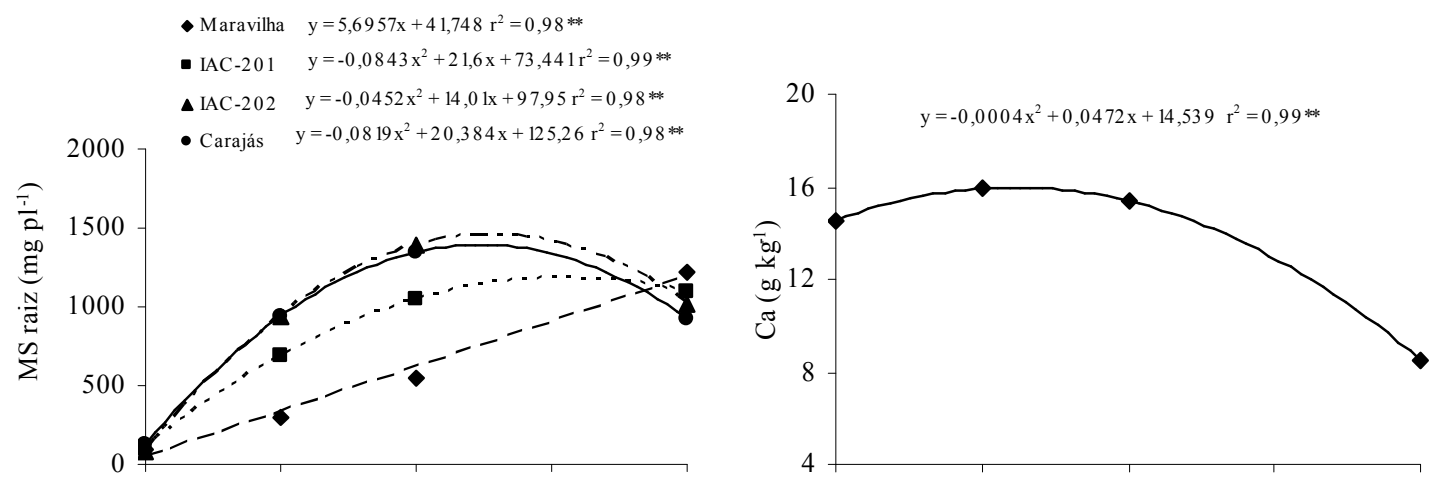

- Maravilha $y=-0,0003 \mathrm{x}^{2}+0,0902 \mathrm{x}+12,821 \mathrm{r}^{2}=0,97^{\text {*e }}$

- IAC-201 $\mathrm{y}=-0,0002 \mathrm{x}^{2}+0,0785 \mathrm{x}+13,62 \mathrm{r}^{2}=0,94$ **

$\triangle$ IAC-202 $\mathrm{y}=0,0187 \mathrm{x}+15,568 \mathrm{r}^{2}=0,96$ **

- Carajás $y=-0,00186286 x^{2}+15,57 x+16,409 r^{2}=0,76 *$
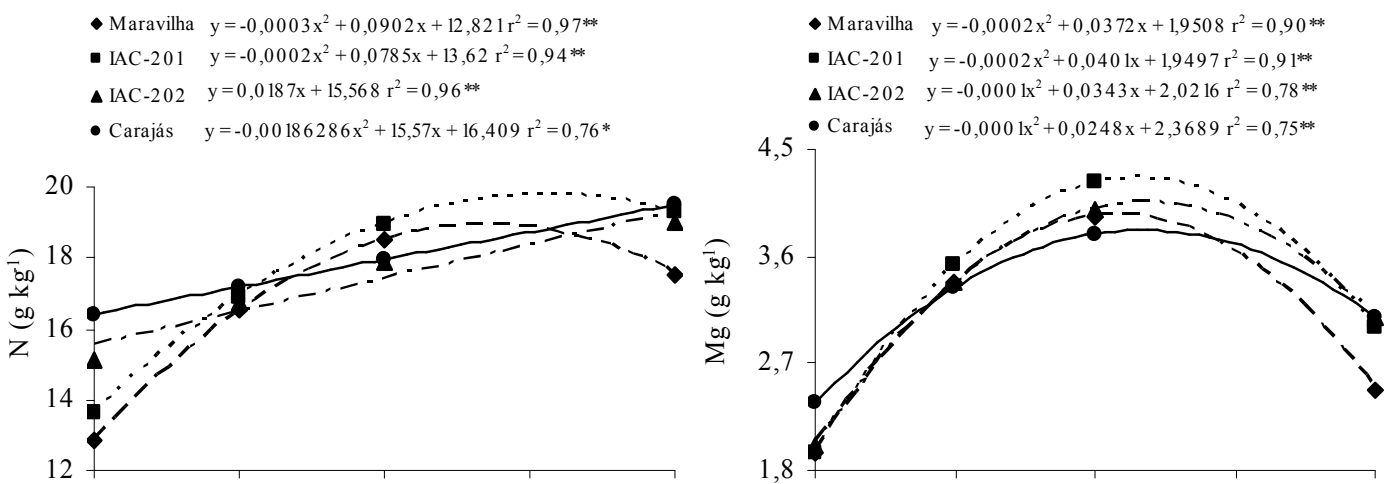

- Maravilha $y=-0,0001 x^{2}+0,0254 x+0,0797 r^{2}=0,96$ **

- IAC-201 $y=-0,0001 x^{2}+0,0216 x+0,0589 r^{2}=0,96$ **

$\Delta$ IAC-202 $y=-0,00005 x^{2}+0,01 x+0,2186 r^{2}=0,27^{* *}$

- Carajás $y=-0,00005 x^{2}+0,0089 x+0,2303 r^{2}=0,28^{* *}$
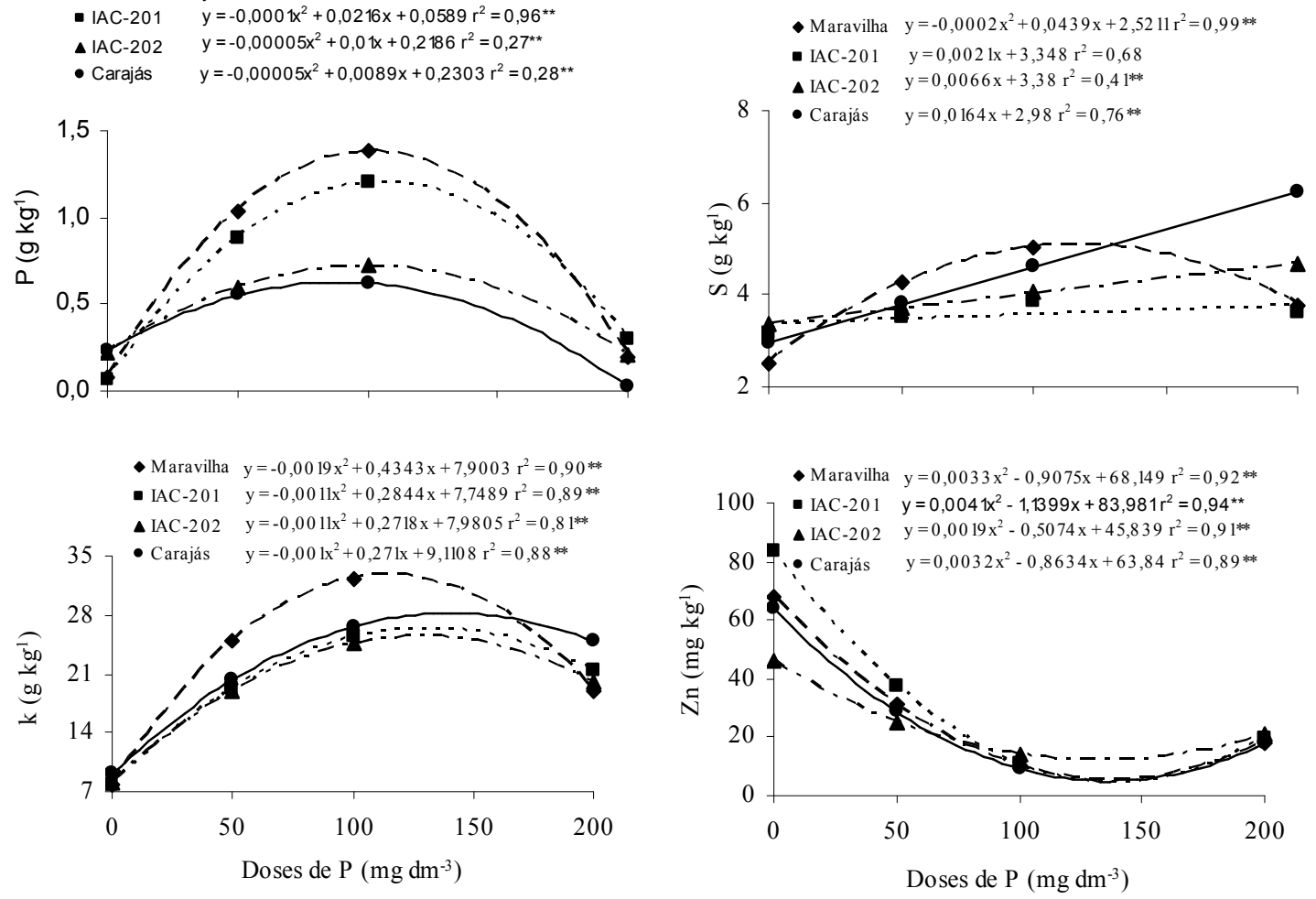

Fonte: Elaboração dos autores. 
$\mathrm{Na}$ ausência de adubação fosfatada, constatouse que a cultivar Carajás possuiu melhor adaptação à condição de baixa disponibilidade de $\mathrm{P}$, pois produziu maior quantidade de massa seca, tanto radicular quanto da parte aérea (Figuras 2 e 3 ).

O acúmulo de massa seca da parte aérea foi similar ao observado para massa seca radicular (Figuras 3), sendo que na cultivar Maravilha a produção de massa seca aumentou de forma linear com a adubação fosfatada, evidenciando a maior exigência à melhoria da fertilidade do solo pelas cultivares do grupo moderno em relação as do grupo intermediário e tradicional (SANT'ANA et al., 2003; FAGERIA; MOREIRA, 2011), ou seja, em muitas situações, necessitam de níveis mais elevados para atingirem a máxima produtividade. As cultivares Carajás, IAC 202 e IAC 201 atingiram a máxima produção de massa seca da parte aérea nas doses de 139, 141 e $182 \mathrm{mg} \mathrm{dm}^{-3}$.

Os resultados diferenciados, quanto ao acúmulo de massa seca da parte aérea entre cultivares de arroz de terras altas decorrente da adubação fosfatada, foi constatada por outros pesquisadores (SANT'ANA et al., 2003; ZOBEL, 2003; WISSUWA, 2005; MALAVOLTA, 2006; FAGERIA, 2007; FAGERIA; MOREIRA, 2011).

Os teores de $\mathrm{N}$ na raiz (Figura 3) e na parte aérea (Figura 3) aumentaram com as doses de P, com comportamento diferenciado entre as cultivares. Carajás e IAC 202 demonstraram-se mais eficientes na extração de $\mathrm{N}$ sob ausência de adubação fosfatada, com maiores teores do elemento tanto na raiz quanto na parte aérea. $\mathrm{O}$ efeito na raiz foi linear e na parte aérea quadrático.

Os maiores teores de $\mathrm{N}$, na raiz e na parte aérea foram observados nas cultivares IAC $201 \mathrm{e}$ Maravilha com a dose de P em torno de $150 \mathrm{mg}$ $\mathrm{dm}^{-3}$ e $140 \mathrm{mg} \mathrm{dm}^{-3}$, respectivamente, tanto na raiz quanto na parte aérea dessas cultivares. A disponibilidade de $\mathrm{P}$ às plantas afeta diretamente o estado nutricional de $\mathrm{N}$, pois há uma interação entre esses dois nutrientes (FAGERIA; MOREIRA; COELHO, 2011a; FAGERIA; BALIGAR; JONES, 2011b). Efeito positivo da adubação fosfata no teor de nitrogênio foi relatado na cultura do milho, onde observou-se elevados teores deste nutriente no tecido foliar com aplicação de fósforo, refletindo em aumento de produtividade (SUMNER; FARINA, 1986). Lira et al. (1996) também reportaram efeito positivo da interação $\mathrm{P}$ x $\mathrm{N}$ no rendimento do capim elefante.

$\mathrm{Na}$ ausência de adubação fosfatada, verificou-se maiores teores de $\mathrm{P}$ na raiz das cultivares Carajás e IAC 202 (Figura 2). Com a aplicação de P o efeito foi positivo e quadrático em todas as cultivares, sendo que na dose em torno de $110 \mathrm{mg} \mathrm{dm}^{-3}$ notouse o máximo acúmulo nas raízes. No entanto, houve diferenças quanto ao incremento desse nutriente, sendo que as cultivares IAC 201 e Maravilha acumulou mais intensamente em relação a adição de $\mathrm{P}$, chegando a teores acima de $1,1 \mathrm{~g} \mathrm{~kg}^{-1}$, enquanto as demais chegaram no máximo de $0,70 \mathrm{~g} \mathrm{~kg}^{-1}$.

Quanto ao teor de P na parte aérea, não houve efeito da interação (Tabela 1) e a adição de fósforo elevou o teor do elemento de forma significativa, com um comportamento quadrático, atingindo valor máximo em torno de $190 \mathrm{mg} \mathrm{dm}^{-3}$ (Figura 3).

Com relação ao desdobramento da interação para teores de $\mathrm{K}$ na raiz e na parte aérea (Figuras 2 e 3), constata-se que a cultivar Maravilha foi a que teve os maiores valores na raiz nas doses de 50 e 100 $\mathrm{mg} \mathrm{dm}{ }^{-3}$, enquanto na parte aérea, na ausência de adubação fosfatada, a cultivar Carajás apresentou o maior teor de $\mathrm{K}$. 
Figura 3. Massa seca de parte aérea (MSPA) e teores de nitrogênio $(\mathrm{N})$, fósforo $(\mathrm{P})$, potássio $(\mathrm{K})$, cálcio $(\mathrm{Ca})$, magnésio $(\mathrm{Mg})$, enxofre(S) e zinco $(\mathrm{Zn})$ na parte aérea, no estádio de diferenciação floral de cultivares de arroz em função de doses de fósforo.
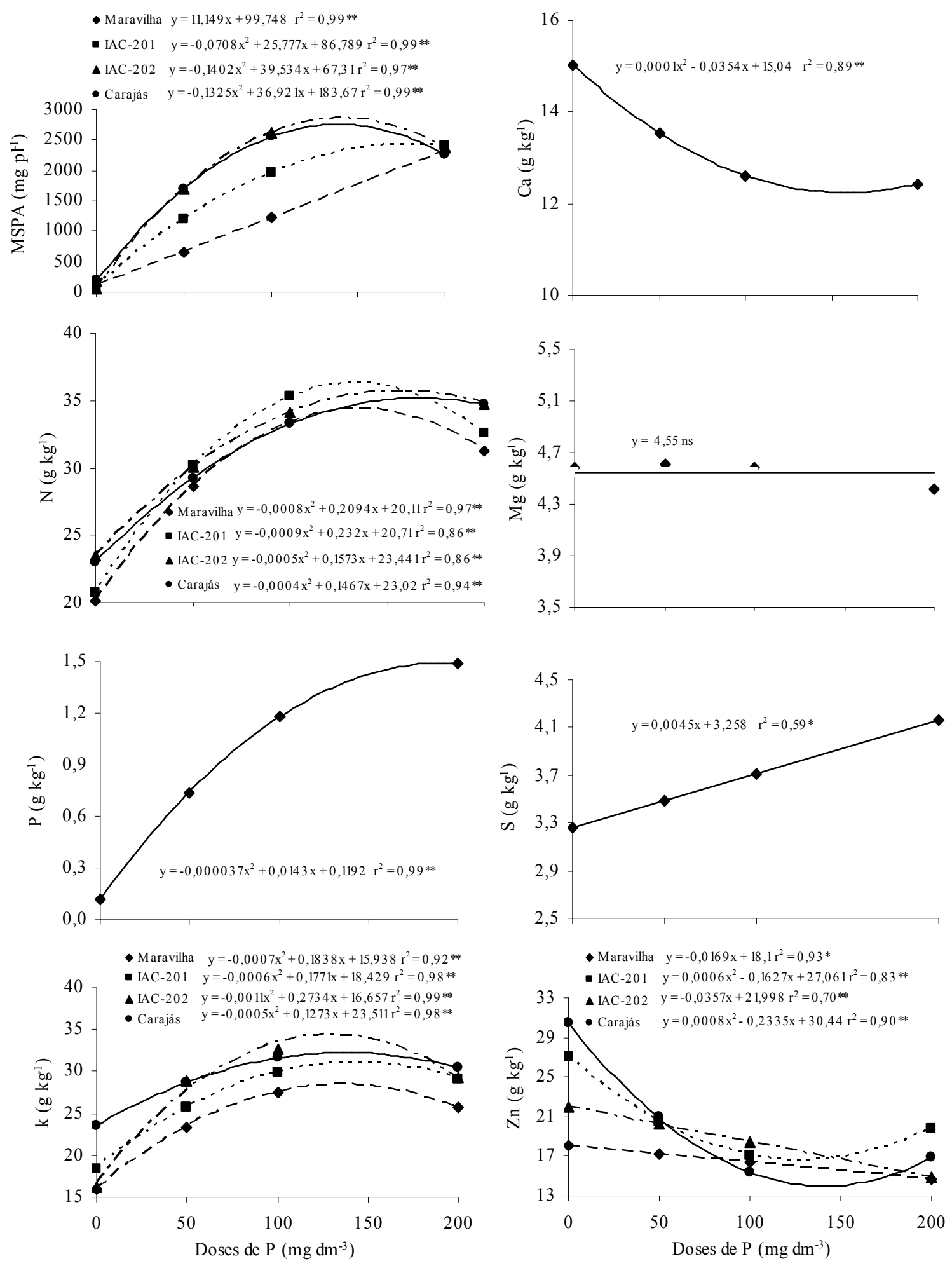

Fonte: Elaboração dos autores. 
A aplicação de $\mathrm{P}$ incrementou o teor de $\mathrm{K}$ na raiz (Figura 2) em todas as cultivares, sendo os resultados bem semelhantes entre as cultivares Carajás, IAC 202 e IAC 201, que atingiram os máximos teores (20 a $25 \mathrm{~g} \mathrm{~kg}^{-1}$ ) em torno da dose de $140 \mathrm{mg} \mathrm{dm}^{-3}$. $\mathrm{O}$ maior teor de $\mathrm{K}$ na raiz foi observado na cultivar Maravilha com a dose em torno de $110 \mathrm{mg} \mathrm{dm}^{-3}$, bem superior aos teores verificados nas demais cultivares com a dose de $140 \mathrm{mg} \mathrm{dm}^{-3}$.

$\mathrm{Na}$ parte aérea (Figura 3), todas as cultivares tiveram incrementos significativos e de forma quadrática à aplicação de $\mathrm{P}$, atingindo maior teor de $\mathrm{K}$ em torno da dose de $140 \mathrm{mg} \mathrm{dm}^{-3}$. O aumento no teor de potássio no sistema radicular e na parte aérea (Figura 2 e 3) pode estar relacionado ao fato de fósforo estimular o crescimento radicular (SANT'ANA et al., 2003; FAGERIA; BALIGAR; LI, 2008; FA GERIA, 2009) o que pode ser observado através do aumento da massa seca de raíz (Figura 2). O contato íon raiz para o $\mathrm{K}$ ocorre através da difusão que é um processo de movimentação do íon a curta distância, assim, à medida que se estimula o crescimento radicular, maior volume de solo é explorado, tornando-se a distância entre o íon e o sistema radicular menor, contribuído desta maneira para maior absorção pelas raízes e transportado para parte aérea (ROSOLEM; SILVA; ESTEVES, 2003; WERLE; GARCIA; ROSOLEM, 2008).

Não observou-se efeito da interação doses de fósforo e cultivares nos teores de $\mathrm{Ca}$ na raiz e na parte aérea (Tabelas 1). Entretanto, observou-se efeito isolado das doses de fósforo com incrementos positivos dos teores de $\mathrm{Ca}$ em ambas as partes das plantas (Figuras 2 e 3). No sistema radicular (Figura 2) houve aumento no teor de Ca até a dose de $60 \mathrm{mg} \mathrm{dm}^{-3}$, e, a partir dessa, houve redução. $\mathrm{Na}$ parte aérea, a aplicação de $\mathrm{P}$ até a dose de $160 \mathrm{mg}$ $\mathrm{dm}^{-3}$ reduziu o teor de Ca. Esse resultado pode ser atribuído à um efeito diluição, uma vez que a massa seca, tanto radicular quanto da parte aérea, aumentou com o aumento da dose de P (Figura 1 e 2), ou, à uma possível complexação de cálcio pelo fósforo, formando fosfato de cálcio (MALAVOLTA, 2006), diminuindo a absorção desse nutriente.
Quanto aos teores de Mg no sistema radicular (Figura 2), constatou-se resultados semelhantes das cultivares. Com a aplicação de $\mathrm{P}$ até $100 \mathrm{mg} \mathrm{dm}^{-3}$ observou-se aumento nos teores de Mg. Nota-se que na ausência de aplicação de $\mathrm{P}$, a cultivar Carajás teve o maior teor. Na parte aérea não houve efeito dos fatores estudados (Tabela 1).

Com exceção da cultivar Maravilha, que teve incremento dos teores de $\mathrm{S}$ de forma quadrática à aplicação de $\mathrm{P}$, as demais cultivares tiveram seus teores de $\mathrm{S}$ no sistema radicular incrementados de forma linear (Figura 2). Os maiores teores foram verificados na cultivar Carajás. Na cultivar Maravilha esse aumento nos teores de $\mathrm{S}$ foi até a dose de $100 \mathrm{mg} \mathrm{dm}^{-3}$ de P. Quanto aos teores de S na parte aérea, constatou-se efeito apenas das doses de $\mathrm{P}$ (Figura 3). Este resultado pode estar relacionado ao provável aumento dos teores de enxofre no solo, decorrente da fonte de $\mathrm{P}$ utilizada, que foi o superfosfato simples. O resultado observado na parte aérea pode ser explicado através do acúmulo de massa seca e pelo teor de $\mathrm{N}$ nessa parte. Essas duas variáveis foram incrementadas positivamente com a aplicação de P. Porém, quando os aumentos não foram lineares, os incrementos ocorreram em altas doses de P. Como o S faz parte de aminoácidos, enzimas e proteínas, o teor desse nutriente foi incrementado (Figura 3) como constatado para o N (Figura 2), uma vez que existe estreita relação entre o conteúdo de nitrogênio e de enxofre nas plantas (FAGERIA; MOREIRA, 2011).

Os teores de $\mathrm{Zn}$, tanto no sistema radicular quanto na parte aérea, foram reduzidos com o incremento da dose de $\mathrm{P}$ (Figuras 2 e 3). No sistema radicular as cultivares tiveram os menores teores com a dose de $140 \mathrm{mg} \mathrm{dm}^{-3}$. Nessa dose, a cultivar IAC 202 teve maior teor que as demais cultivares e, foi a menos afetada pela aplicação de $\mathrm{P}$, donde pode-se inferir que essa cultivar possui um sistema mais eficiente de absorção de Zn em maior disponibilidade de P. Na parte aérea, a redução do teor de Zn foi linear na cultivar do grupo moderno (Maravilha). No entanto, a maior sensibilidade foi constatada com a cultivar 
Carajás, que atingiu o menor valor, em relação aos demais, na dose em torno de $140 \mathrm{mg} \mathrm{dm}^{-3}$.

Vale destacar a diferença significativa entre as cultivares na ausência de aplicação de $\mathrm{P}$, tanto no sistema radicular quanto na parte aérea. A cultivar IAC-201 teve o maior teor de zinco na raiz em relação as demais, enquanto a IAC-202 o menor. Na parte aérea a cultivar Carajás foi a que teve o maior teor de Zn, seguida pela IAC-201, enquanto a Maravilha o menor, ficando evidente a sensibilidade da cultivar Carajás ao efeito do $\mathrm{P}$ sobre a absorção de $\mathrm{Zn}$ e seu teor na parte aérea. A redução dos teores de Zn na planta pela aplicação de P foi decorrente da inibição não competitiva entre esses dois elementos pelos sítios de absorção da planta (MALAVOLTA, 2006; FAGERIA; BALIGAR; LI, 2008; FAGERIA, 2009).

Houve efeito significativo da interação cultivar $\mathrm{x}$ doses de fósforo para a variável crescimento radicular (Figura 4). Esses resultados corroboram com os obtidos por Taylor e Arkin (1981), Rosolem, Silva e Esteves (2003) e Silva et al. (2004) onde o crescimento das raízes foi modificado também por fatores químicos do solo. Assim houve resposta positiva e quadrática das cultivares Carajás, IAC 202 e IAC 201, e linear para o Maravilha. As cultivares Carajás e IAC 202 tiveram os maiores valores em torno de $10 \mathrm{~m}$ planta $^{-1}$, sendo superiores as demais cultivares. A cultivar IAC 201 teve incrementos significativos até a dose em torno de $170 \mathrm{mg} \mathrm{dm}^{-3}$. Já, a Maravilha teve aumentos lineares à adubação fosfatada. No entanto, verificase que o cultivar Carajás, seguido do IAC 201, tiveram maior habilidade em crescer na ausência de adubação fosfatada. Esse comportamento está associado à maior adaptação à condições adversas que os cultivares do grupo intermediário possuem em relação ao grupo moderno (SANTOS; STONE; VIEIRA, 2006).

A absorção de nutrientes por unidade de comprimento de raiz foi significativamente afetada pela adubação fosfatada (Tabela 2). Porém, não foi verificada diferença entre os cultivares, e nem efeito da interação entre os fatores. Assim, por meio da análise de contraste (Tabela 2), também não foi constatada diferença entre os grupos de cultivares, ou seja, a eficiência de absorção de nutrientes foi semelhante entre os grupos. O efeito da adubação fosfatada em todos os nutrientes está representado na Figura 4. A absorção de N, P, K, Ca, Mg, S e $\mathrm{Zn}$ foi incrementada com o aumento da dose de P. Como houve efeito das doses de P nos teores da maioria desses nutrientes, na parte aérea da planta, é possível inferir que na menor dose de $\mathrm{P}$, o crescimento radicular não foi suficiente para manter a planta bem nutrida com os demais nutrientes, não tendo uma velocidade de suprimento para manter o crescimento das plantas, uma vez que houve incrementos significativos da massa seca da planta devido à adubação fosfatada.

Com a aplicação de $\mathrm{P}$, as raízes tiveram melhor desenvolvimento e absorveram os nutrientes em maior velocidade, suprindo a necessidade das plantas (FAGERIA; MOREIRA, 2011). Observouse incrementos na absorção dos nutrientes até aproximadamente a dose de $150 \mathrm{mg} \mathrm{dm}^{-3}$, exceto ao fósforo que foi até a dose de $200 \mathrm{mg} \mathrm{dm}^{-3}$. O aumento na absorção de nutrientes por unidade de comprimento radicular em razão da maior disponibilidade de $\mathrm{P}$, também foi constatado por Rosolem, Assis e Santiago (1994), que verificaram maior absorção de $\mathrm{N}, \mathrm{P}, \mathrm{K}, \mathrm{Ca}$ e $\mathrm{Mg}$ na cultura do milho.

Em função dos resultados obtidos é possível inferir que a disponibilidade de $\mathrm{P}$ é mais limitante para a nutrição da planta do que o crescimento radicular, uma vez que as plantas acumularam significativamente os nutrientes até a dose de 150 $\mathrm{mg} \mathrm{dm}{ }^{-3}$, ou seja, o crescimento radicular nas doses menores não foi suficiente para manter os cultivares com adequado suprimento de nutrientes. 
Tabela 2. Quantidades de nitrogênio, fósforo, potássio, cálcio, magnésio, enxofre e zinco absorvidos por metro de raiz, no estádio de diferenciação floral, de cultivares de arroz de terras altas em função de doses de fósforo.

\begin{tabular}{|c|c|c|c|c|c|c|c|}
\hline Cultivares & $\mathrm{N}$ & $\mathrm{P}$ & $\mathrm{K}$ & $\mathrm{Ca}$ & $\mathrm{Mg}$ & $\mathrm{S}$ & $\mathrm{Zn}$ \\
\hline & & \multicolumn{5}{|c|}{ 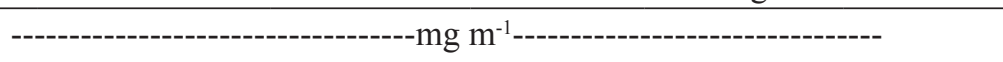 } & $\mathrm{mg} \mathrm{m}^{-1}$ \\
\hline Maravilha & $7800 \mathrm{a}$ & $264 \mathrm{a}$ & $6392 \mathrm{a}$ & $3143 \mathrm{a}$ & $1062 \mathrm{a}$ & $939 \mathrm{a}$ & $4,18 \mathrm{a}$ \\
\hline IAC 201 & 7018 a & $271 \mathrm{a}$ & $6036 \mathrm{a}$ & $2878 \mathrm{a}$ & $1105 \mathrm{a}$ & 809 a & $4,30 \mathrm{a}$ \\
\hline IAC 202 & $7542 \mathrm{a}$ & $254 \mathrm{a}$ & 6619 a & $3044 \mathrm{a}$ & $1087 \mathrm{a}$ & $802 \mathrm{a}$ & $4,02 \mathrm{a}$ \\
\hline \multirow[t]{2}{*}{ Carajás } & 8117 a & $256 \mathrm{a}$ & $7570 \mathrm{a}$ & $3285 \mathrm{a}$ & $1086 \mathrm{a}$ & $952 \mathrm{a}$ & $4,83 \mathrm{a}$ \\
\hline & & & & alor de F & & & \\
\hline Cultivar (C) & $0,91 \mathrm{~ns}$ & $0,04 \mathrm{~ns}$ & $2,54 \mathrm{~ns}$ & $0,71 \mathrm{~ns}$ & $0,05 \mathrm{~ns}$ & $1,46 \mathrm{~ns}$ & $0,91 \mathrm{~ns}$ \\
\hline Doses de $\mathrm{P}(\mathrm{P})$ & $73,72 * *$ & $26,67 * *$ & $78,43 * *$ & $43,8 * *$ & $42,87 * *$ & $43,92 * *$ & $20,74 * *$ \\
\hline $\mathrm{C} \times \mathrm{P}$ & $1,62 \mathrm{~ns}$ & $0,60 \mathrm{~ns}$ & $0,97 \mathrm{~ns}$ & $0,54 \mathrm{~ns}$ & $0,90 \mathrm{~ns}$ & $0,93 \mathrm{~ns}$ & $0,52 \mathrm{~ns}$ \\
\hline Contraste (M x I) & $1,32 \mathrm{~ns}$ & $0,98 \mathrm{~ns}$ & $1,05 \mathrm{~ns}$ & $0,69 \mathrm{~ns}$ & $0,45 \mathrm{~ns}$ & $0,71 \mathrm{~ns}$ & $1,09 \mathrm{~ns}$ \\
\hline C.V. $(\%)$ & 25,6 & 59,6 & 24,7 & 26,2 & 28,8 & 30,5 & 34,0 \\
\hline
\end{tabular}

Médias seguidas de mesma letra não diferem pelo teste Tukey a 5\%. M e I representam os grupos de cultivares moderno e intermediário, respectivamente. ${ }^{* *}$ e ns, significativo a $1 \%$ e não significativo, respectivamente.

Fonte: Elaboração dos autores.

Com relação à eficiência de utilização do fósforo, verifica-se que houve interação entre os fatores cultivares $\mathrm{x}$ doses de fósforo (Tabela 3). As cultivares Carajás e IAC 202 tiveram eficiência significativamente maior em relação aos demais. No desdobramento de cultivares dentro de doses de $\mathrm{P}$, constata-se efeito significativo apenas nas doses 0 e $50 \mathrm{mg} \mathrm{dm}^{-3}$. Na dose 0 , verifica-se que as cultivares Carajás e IAC 202 tiveram eficiência significativamente superior as cultivares IAC 201 e Maravilha. Na dose de $50 \mathrm{mg} \mathrm{dm}^{-3}$, a eficiência da cultivar IAC 202 reduziu-se significativamente enquadrando-se no nível dos demais (IAC 201 e Maravilha) e a Carajás foi muito superior. Nas demais doses a eficiência das quatro cultivares foi semelhante.

Tabela 3. Interação cultivares x doses de fósforo sobre a eficiência de utilização de fósforo.

\begin{tabular}{lcccc}
\hline & \multicolumn{4}{c}{ Doses de $\mathrm{P}\left(\mathrm{mg} \mathrm{dm}^{-3}\right)$} \\
\cline { 2 - 4 } Cultivares & 0 & 50 & 100 & 200 \\
\hline & & mg de massa seca da parte aérea/mg de P acumulado \\
Maravilha & $3740 \mathrm{~b} \mathrm{~A}$ & $1038 \mathrm{~b} \mathrm{~A}$ & $1120 \mathrm{a} \mathrm{A}$ & $860 \mathrm{a} \mathrm{A}$ \\
IAC 201 & $8855 \mathrm{~b} \mathrm{~A}$ & $1209 \mathrm{~b} \mathrm{~A}$ & $1220 \mathrm{a} \mathrm{A}$ & $608 \mathrm{a} \mathrm{A}$ \\
IAC 202 & $71023 \mathrm{a} \mathrm{A}$ & $1308 \mathrm{~b} \mathrm{~B}$ & $969 \mathrm{a} \mathrm{B}$ & $738 \mathrm{a} \mathrm{B}$ \\
Carajás & $71023 \mathrm{a} \mathrm{A}$ & $18806 \mathrm{a} \mathrm{B}$ & $771 \mathrm{a} \mathrm{C}$ & $894 \mathrm{a} \mathrm{C}$ \\
\hline
\end{tabular}

Médias seguidas de mesma letra, maiúscula na horizontal e minúscula na vertical, não diferem pelo teste Tukey a 5\%.

Fonte: Elaboração dos autores. 
Figura 4. Comprimento radicular e quantidade de nutrientes absorvidos por metro de raiz: N, P, K, Ca, Mg, S e Zn na parte aérea, no estádio de diferenciação floral de cultivares de arroz, em função de doses de fósforo.
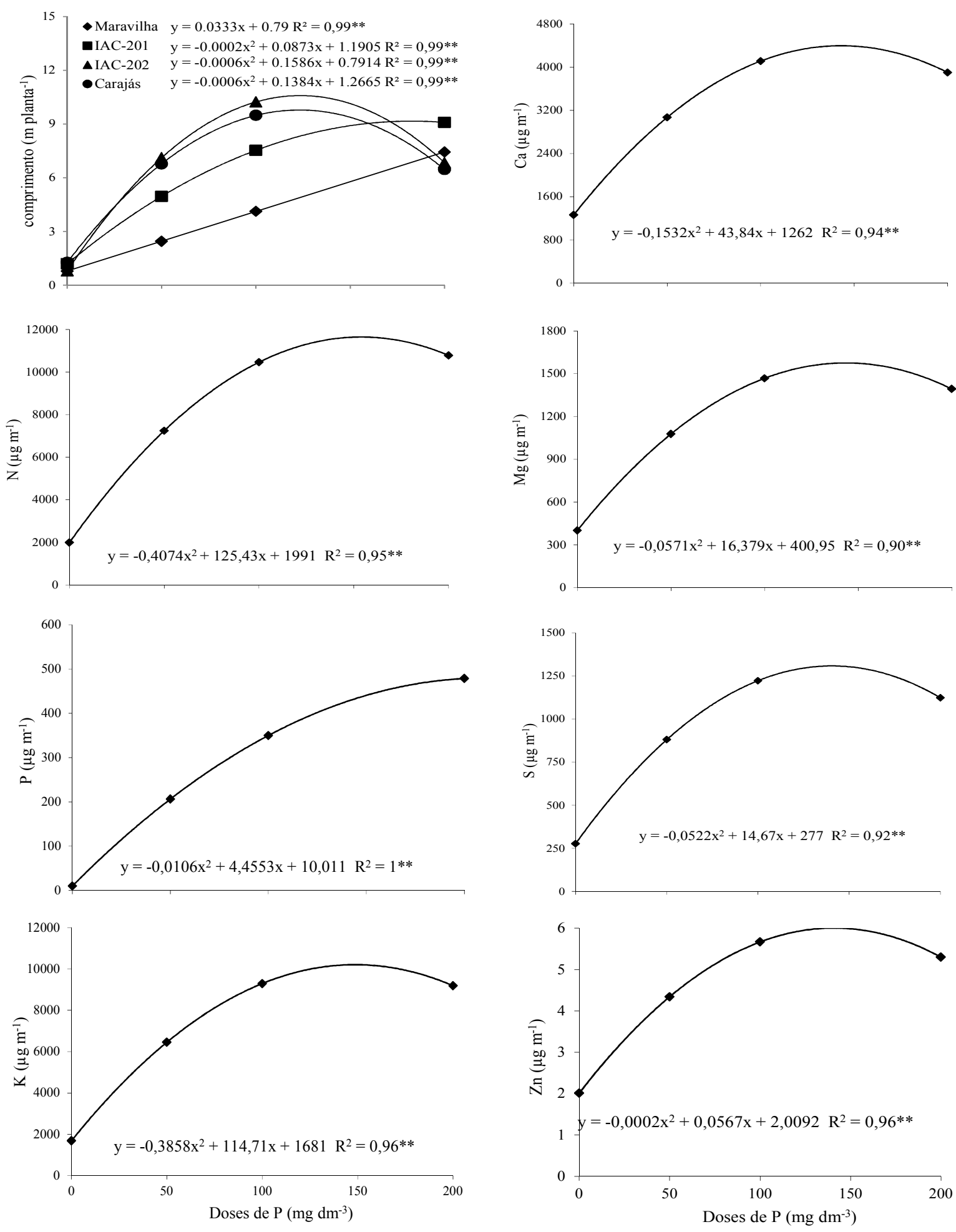

Fonte: Elaboração dos autores. 
Quanto ao desdobramento doses dentro de cultivares, verificou-se efeito somente nas cultivares Carajás e IAC 202. Nas demais (IAC 201 e maravilha) a aplicação de $\mathrm{P}$ não alterou a eficiência de utilização. O cultivar IAC 202 teve eficiência significativamente maior na dose 0 em relação as demais, que não diferiram entre si. Já a Carajás, o aumento da adubação fosfatada até a dose de 100 $\mathrm{mg} \mathrm{dm}{ }^{-3}$ reduziu significativamente a eficiência, tendo diferença entre as três primeiras doses.

As diferenças na eficiência de utilização de $\mathrm{P}$ pelas cultivares de arroz de terras altas temse revelado significativas entre cultivares, onde pode-se fazer a separação em quatro grupos: 1 . cultivares eficientes e não responsivos, 2. cultivares eficientes e responsivos, 3. cultivares não eficientes e responsivos, e, 4. cultivares não eficientes e não responsivos (SANT'ANA et al., 2003; FAGERIA, 2007).

Verifica-se que sob baixa disponibilidade de $\mathrm{P}$ (dose $0 \mathrm{mg} \mathrm{dm}^{-3}$ ) a relação raiz/parte aérea foi maior que $1 \mathrm{e}, \mathrm{com}$ à aplicação de $\mathrm{P}$ a relação foi reduzindo até chegar no menor valor na dose em torno de 140 $\mathrm{mg} \mathrm{dm}{ }^{-3}$ (Figura 5). Esses resultados confirmam os relatos de que a planta sob baixa disponibilidade de $\mathrm{P}$, prioriza o crescimento radicular em detrimento da parte aérea de forma a aumentar a exploração de um volume de solo maior em busca de recursos, no caso o P, como relatado por Fageria e Moreira (2011).

Figura 5. Relação: massa seca radicular (MSRA)/massa seca da parte aérea (MSPA) em função da adubação fosfatada (estádio de diferenciação floral).

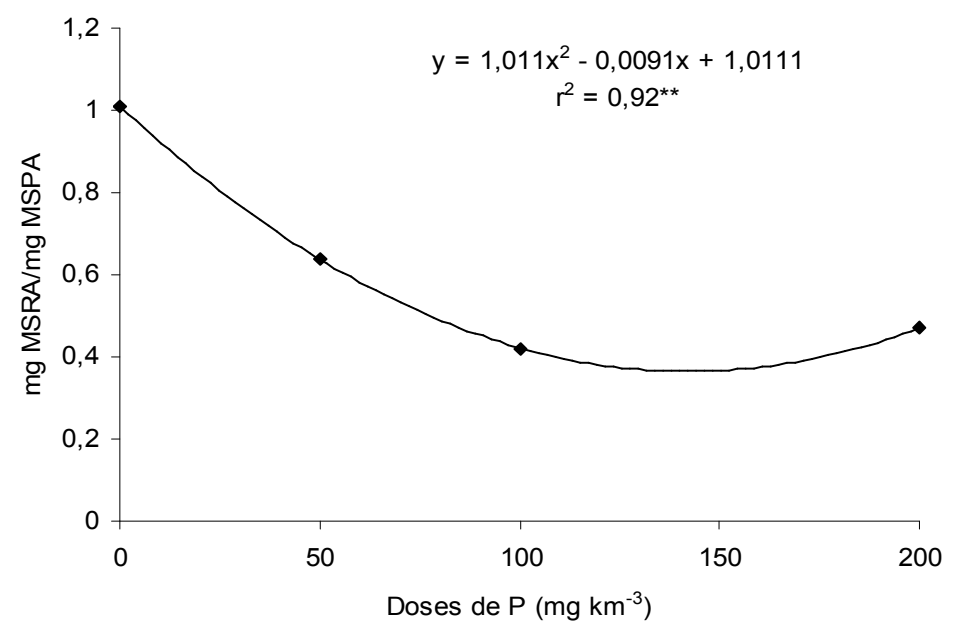

Fonte: Elaboração dos autores.

\section{Conclusões}

Houve aumento da disponibilidade de fósforo no solo com o aumento das doses aplicadas;

Sob baixa disponibilidade de fósforo as cultivares do grupo intermediário tem maior desenvolvimento do sistema radicular e da parte aérea em relação a cultivar do grupo moderno;
A variação nos níveis de fósforo do solo afetou os teores de nutrientes no sistema radicular e na parte aérea das cultivares de arroz;

$\mathrm{O}$ aumento da dose de fósforo incrementou a absorção dos nutrientes por metro de raiz;

Apesar de ter sido constatado maior crescimento radicular devido a maior disponibilidade de 
fósforo, sob baixa disponibilidade desse nutriente o crescimento radicular foi maior em detrimento do crescimento da parte aérea.

\section{Agradecimentos}

À FAPESP pelo financiamento da pesquisa e ao CNPq pela concessão de bolsa ao primeiro autor.

\section{Referências}

EMPRESA BRASILEIRA DE PESQUISA AGROPECUÁRIA - EMBRAPA. Sistema brasileiro de classificação de solos. 2. ed. Rio de Janeiro: Embrapa Solos, 2006.

FAGERIA, N. K.; BALIGAR, V. C.; JONES, C. A. Growth and mineral nutrition of field crops. Boca Raton: CRC Press, 2011b. 640 p.

FAGERIA, N. K. The use of nutrients in crops plants. Boca Raton: CRC Press, 2009. 430 p.

FAGERIA, N. K. Yield physiology of rice. Journal of Plant Nutrition, New York, v. 30, n. 1, p. 843-879, 2007.

FAGERIA, N. K.; BALIGAR, V. C. Ameliorating soil acidity of tropical Oxisols by liming for sustainable crop production. Advances in Agronomy, New York, v. 99, n. 2, p. 345-399, 2008.

FAGERIA, N. K.; BALIGAR, V. C.; LI, Y. C. The role of nutrient efficient plants in improving crop yields in the twenty first century. Journal of Plant Nutrition, New York, v. 31, n. 6, p. 1121-1157, 2008.

FAGERIA, N. K.; MOREIRA, A.; COELHO, A. M. Yield and yield components of upland rice as influenced by nitrogen sources. Journal of Plant Nutrition, New York, v. 34, n. 1, p. 361-370, 2011 a.

FAGERIA, N. K.; STONE, L. F. Physical, chemical, and biological changes in the rhizosphere and nutrient availability. Journal of Plant Nutrition, New York, v. 29, n. 7, p. 1327-1356, 2006.

FAGERIA, N. K; MOREIRA, A. The role of mineral nutrition on root growth of crop plants. Advances in Agronomy, New York, v. 110, n. 1, p. 251-331, 2011.

FENG, L. P.; BOUMAN, B. A. M.; TUONG, T. P.; CABANGON, R. J.; LI, Y. L.; LU, G. A.; FENG, Y. H. Exploring options to grow rice under water-short conditions in northern China using a modeling approach. I: Field experiments and model evaluation. Agriculture Water Management, Maryland, v. 88, n. 3, p. 1-13, 2007.
GUIMARÃES, C. M.; STONE, L. F.; NEVES, P. C. F. Resposta de arroz de terras altas ao estresse de fósforo no solo. Revista Brasileira de Engenharia Agrícola e Ambiental, Campina Grande, v. 11, n. 6, p. 578-584, 2007.

HORST, W. J.; KAMH, M.; JIBRIN, J. M.; CHUDE, V. $\mathrm{O}$. Agronomic measures for increasing $\mathrm{P}$ availability to crops. Plant and Soil, Dordrecht, v. 237, n. 2, p. 211-223, 2001.

LEAL, J. R.; VELOSO, A. C. S. Adsorção de fosfato em latossolos sob vegetação de cerrado. Pesquisa Agropecuária Brasileira, Brasília, v. 8, n. 7, p. 81-88, 1973.

LIRA, M. de A.; FARIAS, I.; FERNANDES, A. de P. M.; SOARES, L. M.; DUBEUX JUNIOR, J. C. B. Efeito da adubação nitrogenada e fosfatada no rendimento do capim elefante (Pennisetum purpureum, Schum). Pesquisa Agropecuária Brasileira, Brasília, v. 31, n. 1, p. 19-26, 1996.

MALAVOLTA, E. Manual de nutrição mineral de plantas. Piracicaba: Agronômica Ceres, 2006. 638 p.

NASCENTE, A. S.; KLUTHKOUSKI, J.; RABELO, R. R.; OLIVEIRA, P.; COBUCCI, T.; CRUSCIOL, C. A. C. Desenvolvimento e produtividade de cultivares de arroz de terras altas em função do manejo do solo. Pesquisa Agropecuária Tropical, Goiânia, v. 41, n. 2, p. 186-192, 2011a.

NASCENTE, A. S.; KLUTHKOUSKI, J.; RABELO, R. R.; OLIVEIRA, P.; COBUCCI, T.; CRUSCIOL, C. A. C. Produtividade do arroz de terras altas em função do manejo do solo e da época de aplicação de nitrogênio. Pesquisa Agropecuária Tropical, Goiânia, v. 41, n. 1, p. 60-65, 2011b.

OLIVEIRA JUNIOR, A. de; PROCHNOW, L. I.; KLEPKER, D. Soybean yield in response to application of phosphate rock associated with triple superphosphate. Scientia Agricola, Piracicaba, v. 68, n. 3, p. 376-385, 2011.

QU, Y.; PING, M.; HONGLIANG, Z.; CHEN, Y.; GAO, Y.; TIAN, Y.; WEN, F.; LI, Z. Mapping QTLs of root morphological traits at different growth stages in rice. Genetica, New York, v. 133, n. 2, p. 187-200, 2008.

ROSOLEM, C. A.; SILVA, R. S.; ESTEVES, J. A. F. Potassium supply to cotton roots as affected by potassium fertilization and liming. Pesquisa Agropecuária Brasileira, Brasília, v. 38, n. 5, p. 635-641, 2003. 
ROSOlEM, C. A.; ASSIS, J. S.; SANTIAGO, A. D. Root growth and mineral nutrition of corn hybrids as affected by phosphorus and lime. Communications in Soil Science and Plant Analysis, New York, v. 25, n. 1314, p. 249-254, 1994.

ROTILI, E. A.; FIDELIS, R. R.; SANTOS, M. M.; BARROS, H. B.; PINTO, L. C. Eficiência do uso e resposta à aplicação de fósforo de cultivares de arroz em solos de terras altas. Bragantia, Campinas, v. 69, n. 3, p. 705-710, 2010.

SANT'ANA, E. P.; SANT'ANA, E. V. P.; FAGERIA, N. K.; FREIRE, A. B. Utilização de fósforo e características do sistema radicular e da parte aérea da planta de arroz. Ciência Agrotecnologia, Lavras, v. 27, n. 2, p. 370-381, 2003.

SANTOS, A. B.; STONE, L. F.; VIEIRA, N. R. A. $A$ cultura do arroz no Brasil. 2. ed. Santo Antônio de Goiás: Embrapa Arroz e Feijão, 2006. 1000 p.

SILVA, L. M. da; LEMOS, L. B.; CRUSCIOL, C. A. C.; FELTRAN, J. C. Sistema radicular de cultivares de feijão em resposta à calagem. Pesquisa Agropecuaria Brasileira. Brasília, v. 39, n. 7, p. 701-707, 2004.
SUMNER, M. E.; FARINA, M. P. W. Phosphorus interaction with other nutrients and lime infield cropping systems. Advance in Soil Science, New York, v. 5, n. 2, p. 201-36, 1986.

TAYLOR, D.; ARKIN, G. F. Root zone modification fundamentals and alternatives. In: Modifying the root environment to reduce crop stress. St. Joseph: ASAE, 1981. p. 3-16.

TENNANT, D. A test of a modified line intersect method of estimating root length. Journal of Ecology, Oxford, v. 63, n. 3, p. 995-1001, 1975.

WERLE, R.; GARCIA, R. A.; ROSOLEM, C. A. Lixiviação de potássio em função da textura e da disponibilidade do nutriente no solo. Revista Brasileira de Ciência do Solo, Viçosa, v. 32, n. 6, p. 2297-2305, 2008.

WISSUWA, M. Combining a modeling with a genetic approach in establishing associations between genetic and physiological effects in relation to phosphorus uptake. Plant and Soil, Dordrecht, v. 269, n. 1-2, p. $57-$ 68, 2005.

ZOBEL, R. W. Sensitivity analysis of computer based diameter measurement from digital images. Crop Science, Madison, v. 43, n. 2, p. 583-591, 2003. 